\title{
Novel Hydrogen Probe for Al Melt
}

\author{
C.O. Park ${ }^{1}$, Young Chang Yang ${ }^{2}$, B. Jung ${ }^{3}$ \\ ${ }^{1}$ Dept. of MSE, KAIST, Daejon, KOREA \\ Email: cops@kaist.ac.kr \\ ${ }^{2}$ Samsung Electronics \\ ${ }^{3}$ Dept. of MSE, KAIST, Daejon, KOREA
}

\begin{abstract}
These days the use of $\mathrm{Al}$ is ever-increasing as a building block for construction as well as aerospace industry and electronic home appliances because of its high strength with light weight and good surface appearances. However as the strength of the Al alloy increases, it is more susceptible to hydrogen which is incorporated in the melt through the decomposition of the humidity in the ambient[1]. The object of this study is to achieve a stable electrochemical hydrogen sensor which can be used in a harsh environment of Al alloy melts.
\end{abstract}

Key words: Hydrogen sensor, Proton conductor, Titanium, $\mathrm{CaZr} \mathrm{r}_{0.9} \mathrm{In}_{0.1} \mathrm{O}_{3-\delta}$

\section{Experiments}

The high temperature proton conductor of $\mathrm{CaZr}_{0.9} \mathrm{In}_{0.1} \mathrm{O}_{3-\delta}$ was used to fabricate the sensor of Eq. (1) due to its high mechanical strength and high chemical stability. The schematic structure of the sensor is shown in Fig.1 with its optical images where the reference materials of $\mathrm{TiH}_{2} / \mathrm{Ti}[2,3]$ has been used.

$$
\mathrm{Pt}, \mathrm{H}_{2}, \mathrm{Ti}, \mathrm{TiH}_{2}, \mathrm{TiO}_{\mathrm{CaZr}} \mathrm{r}_{1-\mathrm{x}} \ln _{\mathrm{x}} \mathrm{O}_{3-\delta} \mid \mathrm{H}_{2}, \mathrm{Pt}
$$
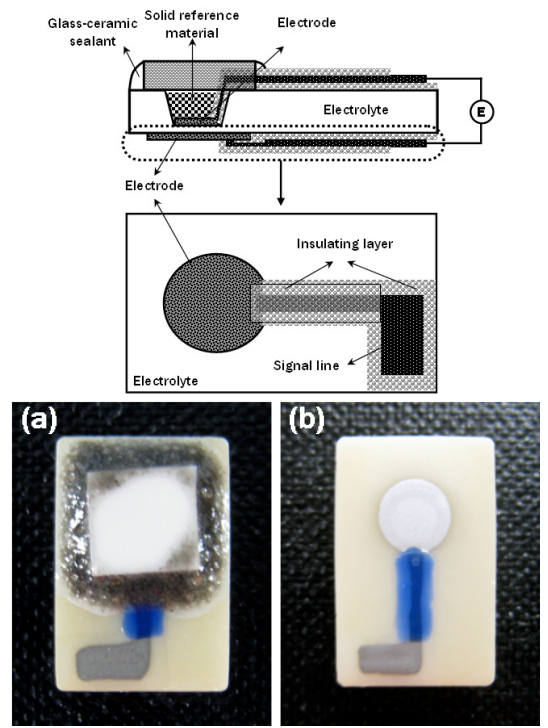

Fig. 1. Schematic view of the hydrogen sensor; (a) Top view (b) Bottom view.

\section{Results}

The fabricated sensor has been measured for various hydrogen concentrations $(0.1 \%$ to $10 \%)$ at temperatures ranged from $723 \mathrm{~K}$ to $1123 \mathrm{~K}$ in Fig. 2(a). It shows sensitivity of more than $99 \%$ of theoretical value at more than $923 \mathrm{~K}$ and about $95 \%$ at $723 \mathrm{~K}$ to $823 \mathrm{~K}$ as shown in Fig. 2(b).
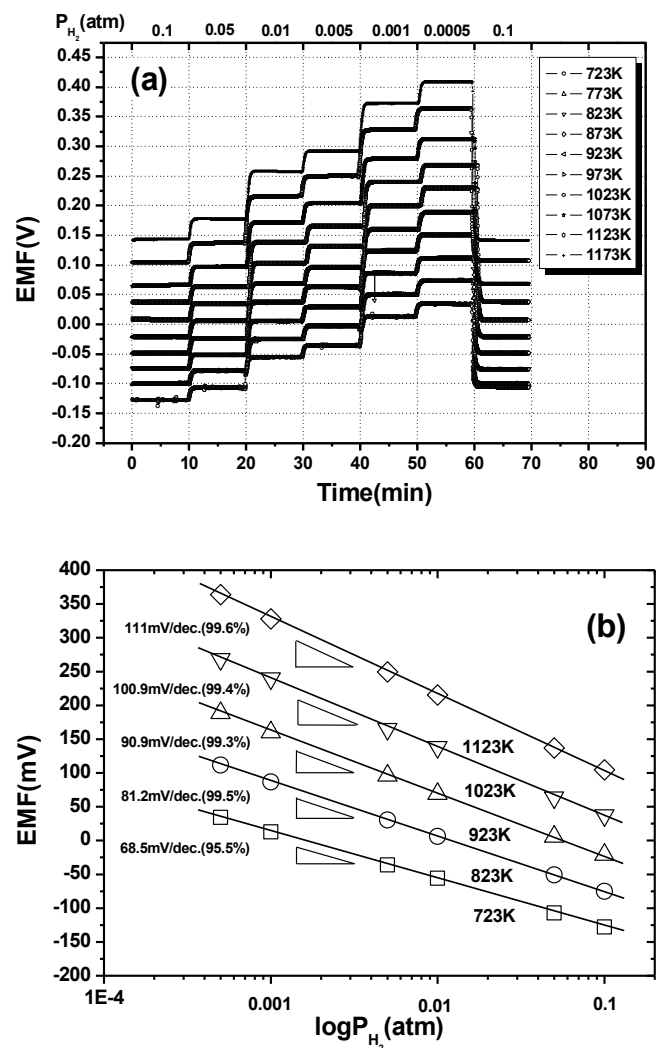

Fig. 2. EMF responses of the hydrogen sensor at various temperatures; (a) transient behaviors as a function of hydrogen concentration and (b) their sensitivities. 


\section{Conclusions}

The hydrogen sensor made of In doped $\mathrm{CaZrO}_{3}$ electrolyte and the solid reference material of $\mathrm{Ti} / \mathrm{TiH}_{2} / \mathrm{TiO}$ exhibits the hydrogen concentration -dependent response of EMF with a speed of less than 40 seconds at 500 to $900^{\circ} \mathrm{C}$, having almost Nernstian sensitivity. It gives reproducible results for about 60 hours continuous use in the controlled hydrogen atmosphere.

\section{References}

[1] C. O. Park, J. W. Fergus, N. Miura, Jinsu Park, Angi Choi, Solid-state electrochemical gas sensors, lonics 15, 261-284 (2009).

[2] C. Schwandt, D.J. Fray, The titanium/hydrogen system as the solid-state reference in hightemperature proton conductor-based hydrogen sensors, J. Applied. Electrochemistry. 36, 557565 (2006).

[3] D.P. Lapham, C. Schwandt, M.P. Hills, R.V. Kumar and D.J. Fray, The detection of hydrogen in molten aluminum, lonics 8, 391-401 (2002). 